\title{
Communication of pharmacogenetic research results to HIV-infected treated patients: standpoints of professionals and patients
}

Grégoire Moutel $^{\star}, 1$, Nathalie Duchange ${ }^{1}$, François Raffi ${ }^{2}$, Lama I Sharara ${ }^{1}$, Ioannis Théodorou $^{3}$, Violaine Noël ${ }^{4}$, Sandrine de Montgolfier ${ }^{1}$, Ingrid Callies ${ }^{1}$, François Bricaire ${ }^{5}$, Christian Hervé ${ }^{1}$, Catherine Leport ${ }^{4}$ and the APROCO-COPILOTE Study Group ${ }^{6}$

\footnotetext{
${ }^{1}$ Laboratoire d'Ethique Médicale et Médecine Légale \& Institut International de Recherche en Ethique Biomédicale, Faculté de Médecine Paris 5. 45 rue des Saints-Pères, Paris 75006, France; ${ }^{2}$ CISIH, CHU de Nantes, Hôtel Dieu, 1 Place Alexis-Ricordeau, 44035 Nantes Cedex, France; ${ }^{3}$ Laboratoire d'Immunologie Cellulaire et Tissulaire, INSERM UR 543, Faculté Pitié-Salpêtrière, 47-82, boulevard de l'Hôpital, 75651 Paris cedex 13, France; ${ }^{4}$ Laboratoire de Recherche en Pathologie Infectieuse, Faculté X, Bichat-16, rue Henri Huchard-75870 Paris cedex 18, France; ${ }^{5}$ Service des Maladies Infectieuses et Tropicales. Hôpital Pitié Salpetrière, 47-82 boulevard de l'Hôpital, 75651 Paris Cedex 13, France
}

The aim of pharmacogenetic studies is to adapt therapeutic strategies to individual genetic profiles, thus maximising their efficacy and minimising the likelihood of adverse side effects. Since the advent of personalised medicine, the issue of communicating research results to participants has become increasingly important. We addressed this question in the context of HIV infection, as patients and associations are particularly concerned by research and therapeutic advances. We explored the standpoints of both research professionals and participants involved in a pharmacogenetic study conducted in a cohort of HIVinfected patients. The setting of the research protocol was followed over a 2-year period. Participants' standpoints were collected through a questionnaire and interviews were conducted with research professionals. Of 125 participants, $76 \%$ wished to receive individual results and $71 \%$ wished to receive collective results; $39 \%$ did not know when results might be expected. Communication of global research results is a principle that is generally accepted by professionals. Concerning individual feedback, the professionals felt that it was necessary if it could be of direct benefit to the participant, but they expressed doubts for situations with no recognised benefit. Our results highlight the necessity to consider this issue in greater detail. We suggest the need to anticipate the debates concerning individual feedback, to differentiate between situations and the importance of further investigations on the opportunities and modalities of communication. Finally, our work emphasised the opposite pressures between the pursuit of scientific knowledge and the therapeutic orientation of clinical trials.

European Journal of Human Genetics (2005) 13, 1055-1062. doi:10.1038/sj.ejhg.5201450;

published online 15 June 2005

Keywords: clinical trials; pharmacogenetics; research participants; research result communication; HIV

*Correspondence: $\operatorname{Dr}$ G Moutel, Laboratoire d'Ethique Médicale et Médecine Légale \& Institut International de Recherche en Ethique Biomédicale, Faculté de Médecine Paris 5, 45 rue des Saints-Pères, Paris 75006, France. Tel: + 3301428641 31; Fax: + 3301428641 33; E-mail: moutel@necker.fr

${ }^{6}$ Members of the APROCO study group are listed in the acknowledgements Received 14 February 2005; revised 10 May 2005; accepted 12 May 2005; published online 15 June 2005

\section{Introduction}

Pharmacogenetics studies the genetic factors that may influence the efficacy and toxicity of treatments. It is proving a promising way for HIV therapy and several 
genotype-phenotype associations for HIV have been determined. ${ }^{1-3}$ For example, Martin ${ }^{4}$ has established a genetic component for a clinically significant drug hypersensitivity to abacavir. However, there are, at present, relatively few relevant associations and these need confirmation in larger populations. The medical impact and usefulness of pharmacogenetic testing in HIV are not clear due to the complexity of interfering factors such as gene/gene and gene/environment interactions. As research in pharmacogenetics develops, a number of ethical issues are raised. ${ }^{5,6}$ Our study deals with the feedback of research results to participants.

The question as to whether and how clinical research results should be communicated to participants is an emerging topic, ${ }^{7-11}$ particularly in the domain of pharmacogenetics and HIV infection. ${ }^{1,12-15}$ Two levels of feedback are possible: global and individual. There is currently a consensus that the respect of research participants implies the communication of the global results to them at the end of the research. It has been suggested that it should be the role of research ethic committees (RECs) to ensure such feedback, after setting up the practical means and modalities. ${ }^{10}$ This standpoint was supported by the observation that only $30 \%$ of clinical research results are rendered public. ${ }^{16}$ It has also been argued that making public research results is a duty towards participants. ${ }^{17}$

Communication of individual biological or clinical research data raises questions about their use in a nominative manner and about whether and how to respond to the demands of participants. Is this type of communication appropriate, given that it concerns research results that require further validation and the impacts of which for the patients are still uncertain? Appelbaum ${ }^{18}$ showed that the separation between research and care is sometimes blurred. Indeed, patients may have difficulty distinguishing between the two types of activity as well as between experimental and validated data. All this raises questions concerning the nature of the information to be given to the participant, the ways of managing and explaining the uncertainty inherent to research and lastly, the medical responsibility in play.

These questions are particularly pertinent to pharmacogenetic studies concerning HIV-infected patients. Indeed, because HIV infection is chronic and treatments are long and aggressive, HIV patients are naturally waiting for any scientific progress and information that could have an impact on their day-to-day lives with the disease. This explains why HIV patients' associations actively follow clinical research protocols and are aware of the issues of information and communication to research participants. Our study was performed with HIV-infected patients from the APROCO-COPILOTE cohort. ${ }^{12}$ Patients were asked to participate in a protocol designed to study the progression of the disease, response to treatment and the occurrence of adverse events as a function of genetic polymorphisms.
The DNA Bank Monitoring Committee of the APROCO study (so-called the 'Monitoring Committee') examined the opportunity to give global and/or individual results to research participants. In particular, the committee considered whether individual feedback would be of benefit to the patient and whether it would be pertinent for medical care.

This article illustrates the practical approach adopted by the APROCO study group and describes the results of a study aiming to evaluate the points of view of healthcare professionals and participants. The objective was to analyse criteria and procedures to be considered when communicating results to participants.

\section{Methods}

The APROCO-COPILOTE study is supported by the French National Agency for AIDS Research (ANRSEP11-EP22). The cohort includes $1281 \mathrm{HIV}$-infected patients who started taking a protease inhibitor-containing antiretroviral treatment between 1997 and 1999. ${ }^{19-22}$ A pharmacogenetic research protocol based on the use of DNA extracted from blood samples was initiated in January 2002 and samples were collected until June 2003. The protocol aimed to study genetic markers associated with disease progression as well as markers involved in the occurrence of treatmentassociated adverse events. ${ }^{23-26}$ Together with virological and clinical factors, genetic markers might affect patient health care by providing a better understanding of the factors influencing the response or tolerance to treatment. While setting up the project, the issues of information, consent and result feedback to participants were considered. $^{12}$

The issues were to identify and to analyse the arguments for and against the global and individual communication of research results and to examine how to take into account patients' expectations. Four complementary methods were used:

1. An external observer attended all meetings of the Monitoring Committee to record the arguments and points of view of the different actors concerned. This multidisciplinary committee ${ }^{12}$ consisted of the main investigators, ethics experts, a lawyer, a representative of the study promoter and a representative of patients' associations. Meetings were analysed for content concerning practical issues and relevance of the procedures laid down in the protocol for participant information and result feedback.

2. The scientific professionals involved in the DNA bank project were interviewed to collect the viewpoints of three groups of professionals: (1) fundamental researchers, not involved in clinical care, (2) clinicians involved in the follow-up of patients and (3) the physicians in 
charge of coordinating the project, involved directly or indirectly in care. They were asked to comment on the questions raised by individual and global research result feedback.

3. To analyse participants' attitudes, the consent forms offered the possibility to express their wishes concerning research result feedback. ${ }^{12}$ These forms were analysed in two large centres by a physician to respect confidentiality.

4. The patients followed in 47 centres throughout France were asked to answer five multiple-choice questions concerning: (1) their expectations in terms of global and/or individual results, (2) the time at which they would expect to receive the results, (3) their interest in the information documents, (4) their expectations concerning personalised genetic information and (5) their reasons for participating in the research. The questionnaire, validated by the Monitoring Committee, was issued to patients during consultations with their physician and was returned anonymously. The results are expressed as frequencies of answers.

\section{Results}

\section{Professionals' points of view}

The Monitoring Committee The possible benefits accruing to HIV-infected patients participating in the protocol was the key issue that conditioned the views of healthcare professionals about the communication of results. This was discussed at all six committee meetings held over the 18-month study period and a clear distinction was made between global and individual result feedback.

After stating the arguments in favour of a hypothetical benefit, ${ }^{12}$ the professionals discussed the uncertainty of the impact of the results. It was pointed out that the impact of certain genetic markers on medical care was unclear and that it could not be ruled out that, for some patients, knowledge of their genetic profile could have unpredictable consequences on their experience of both illness and treatment. It was stressed that questions concerning result disclosure arise at three phases of the research:

(1) At the time of inclusion it concerns the information relating to result feedback. The professionals were particularly concerned by the consent form. ${ }^{12}$

(2) During the research it concerns the information about the selection of the genetic markers to be studied, taking into account scientific progress and potential medical impacts. The aim was to make the most pertinent choices, given the precious nature of the samples and their limited size. The investigators, therefore, sought to achieve a balance between scientific imperatives and a search for the greatest possible clinical benefits. To keep the participants informed of these choices, an information document for physicians was produced once per year including a sheet to be delivered to the participants during their follow-up visits. The aim of this document was to encourage physicians to provide oral information concerning overall results during follow-up visits.

(3) At the end of the research it concerns the decisions as to whether and how to provide global and/or individual feedback. The committee insisted that this debate took place well before the first results were obtained to define the best ways managing global and/or individual results communication.

The debate about the possibility of offering participants access to individual results remained open. Arguments in favour included the wish to establish a real partnership with participants and arguments against included the wish to protect the patient and to avoid generating anxiety or false hopes.

Results of interviews Four researchers, six clinicians and five co-ordinating physicians were interviewed. All of them agreed that the global research results should be communicated to participants. However, the difficulty in explaining genetic results and the need to express scientific data in simple language were stressed by the physicians. It was suggested that global results should be communicated for the benefit of the participant, in the form of a letter or short note, with comments on the results obtained and details of the meetings and published articles in which the results had been presented.

The communication of individual results was a source of disagreement between the three categories, although there was a consensus about the necessity to plan and to anticipate this possibility. All the interviewees mentioned the need to train clinicians to deliver individual genetic results. They stressed the need for these results to be communicated by a physician, implying that he/she knows how to interpret the genetic data and can explain the significance of the results and their impact on clinical care. Several clinicians were convinced that the patients had agreed to provide samples on the assumption that they would receive individual feedback. Some suggested that the decision to communicate results should be made on a case-by-case basis and pointed out the difficulty in making this decision before data are available. The professionals distinguished between two situations: (1) benefit to the participant, a situation that clearly favours individual feedback, and (2) no recognised benefit, a situation that left the question open. It was pointed out that if the patient is informed that a particular genetic marker is associated with an increased medical risk, this patient is likely to ask about his/her own personal risk. It was also stressed that the participant should receive information 
about the relative level of risk, the notion of uncertainty, as well as the predictive rather than absolute nature of genetic determinism. Indeed, individual genetic results might be negative for the patient due to the uncertainty of how he/she will interpret his result in term of personal risk. The physicians responsible for coordinating the project raised the issue of individual feedback and the need to consider the participants in a personalised manner, adapted to their situation, when communicating results.

Clinicians thought that using the term 'benefit' was an important factor in encouraging patients to engage in the research protocol. One physician said that it might lead the participant to think that the research would have practical personal repercussions. For researchers, the term 'benefit' could lead to confusion in the minds of participants concerning the chronology of the outcomes of research. They felt that it was the responsibility of the clinicians to explain the meaning of 'benefit' and to differentiate between the benefit associated with participation in terms of follow-up and the benefit that might result solely from the data generated by the research. The physicians coordinating the project stated that the benefits could not be summed up simply in terms of consequences of the results on healthcare but that they also consisted of improvements in patient management through participation in the research itself, with regular general and psychological follow-up, involving standardised evaluation of the status of infection and complications.

\section{Participants' points of view}

Option concerning the communication of results in the consent form In 121 consent forms analysed, 54\% of the participants indicated their wish to be informed of the results, even if they had no immediate impact on their treatment. Only half of them provided their contact details or those of their physician. When personal contact details were provided, it was most frequently a telephone number, more rarely an address and exceptionally both. Among the $42 \%$ of participants who did not indicate their choice, onefifth gave personal contact details. Only $4 \%$ clearly rejected the option of being informed of the results and did not leave contact details.

Expectations of participants in terms of result feedback In all, 2 centres agreed to distribute the questionnaire, which was returned by 125 participants. In total, $76 \%$ wished to receive individual and $71 \%$ wished to receive collective results (Table 1 , question 1). Just $8 \%$ expressed no expectation of receiving any type of result. Less than one-third said that they regularly read the annual information document (Table 1, question 2). This was not due to distribution problems because only four participants commented that they were unaware of this document and regretted this. We found that $37 \%$ expected to receive results within one year and that 19\% even expected results
Table 1 Answers of 125 HIV-infected treated participants in the APROCO cohort to 4 questions dealing with research results

$\%$

Question 1: Do you expect to receive information about the results? For the whole group? Related specifically to yourself? Global and individual

Global only

None

12

Don't know

Question 2: Do you read the annual document of information at the intention of the research participants and addressed by the physician?

Yes, occasionally $\quad 40.8$

No, never 36

Yes, regularly $\quad 17.6$

No reply

5.6

Question 3: When do you think that the results for the genetic research protocol will be available?

Less than 6 months

19.2

6 months to 1 year

18.4

1 to several years

19.2

Don't know

43.2

Question 4: What, in your opinion, are the advantages and disadvantages of having access to personalised genetic information? (Several responses possible)

Treatment adapted to my personal needs 76

Possibility of prevention

Understanding of disease progression

Intrusion in private life

Don't know

Other, specify

within six months (Table 1, question 3). A high percentage of the participants (39\%) did not know when results might be expected. When asked about the possible advantages and disadvantages of having access to personalised genetic information, $76 \%$ cited the possibility of adapting the treatment to the person, $72 \%$ cited the possibility of knowing about the progression of the disease and 39\% foresaw opportunities for prevention (Table 1, question 4). Only $7 \%$ had no opinions on this issue. The disadvantages were rarely mentioned, with intrusion into private life being cited in 5\% of cases: no other disadvantages were mentioned. When questioned about their motivations for participating in research (Table 1, question 4), a high percentage (85\%) answered that they hoped for discoveries that would be useful to all patients. The hope of discoveries useful for themselves was the next most frequent response (67\%). They also cited the possibility of better follow-up (30\%) and greater involvement in the management of their own disease (24\%). The minimal nature of the constraints imposed was cited in $16 \%$ of cases. The motive for participation was rarely a desire to please the physician and never due to a passive attitude linked to a difficulty in 
refusing. One patient cited 'recognition of the medical assistance I am receiving.'

\section{Discussion}

Whether results should be given to research participants is a complex question that is encountered in research in general and in research for genetic markers more particularly. ${ }^{11,12,27,28}$ There is an international consensus that overall results should be communicated to patients after publication and after being peer-reviewed by the scientific community. ${ }^{7,29}$ However, studies show that only a small number of clinical trials are actually published. ${ }^{10,16,17}$ In France, a law concerning patients' rights $^{30}$ made the transmission of global results to research participants mandatory in 2002.

In our study, the members of the APROCO cohort who agreed to participate in this pharmacogenetic study clearly expressed the wish to have access to both global and individual research results, even if they had no impact on their medical care. This reflects the need for feedback as an acknowledgement of their contribution to the research that may help them to better understand their disease. It probably also explains our results showing that patients take part in research for altruistic reasons, while hoping at the same time for personal benefits.

Most professionals involved in the APROCO research are in favour of informing participants of the global results. Feedback may be viewed differently according to the study population and the severity of the disease when research may generate new care and treatment options. This is particularly true for HIV-infected patients and for protocols that are presented as having potential benefits. It is difficult to predict individual behaviours even when faced with global results; some individuals will be tempted to identify their own results, and the uncertainty associated with these data might trigger anxiety. Genetic and HIV provided a combination, which favoured the emergence of demand for access to research results and the interaction between patients and the scientific community.

Our work underlines the importance of adapting the major ethical principles applied in clinical research ${ }^{31}$ to the specific issues raised by pharmacogenetics. ${ }^{5,6}$ Indeed, these principles should evolve with time. To fulfil the ethical issue of transparency with respect to information and consent, the initial information should be completed, if necessary, to take into account research developments, its outcomes and results. Out of loyalty to the patient, if the study changes considerably or new genes are studied, asking for a new consent should be considered. Furthermore, as in any other protocol, but in a more sensitive manner (due to the representation of genetic, its impact on the future well-being of the individual and his family), the respect for confidentiality and privacy is required as well as the necessity to educate the patient on the nature of pharmacogenetic data in term of medical impact. ${ }^{5,6}$ This would allow the patients to decide to participate in the protocol in a truly informed way, knowing about the riskbenefit ratio, and to allow them to withdraw from the study at any time as a consequence of information given to them. The right not to know as well as the participants changing their mind, particularly in long-term studies, need to be considered. During the delivering of information and consent, this needs to be integrated from the start within the doctor-patient relationship. This is particularly important when dealing with data that are significant for the participants' health as added to the Helsinki declaration in Tokyo in 2004 on ethical principles for medical research involving human subjects ${ }^{31}$ and emphasise the need for research ethics committees to evolve in the accompanying of research protocols and cohorts.

\section{Ethical issues of the initial information given to the participants: the uncertainty of benefit}

To avoid false hopes, our results show that the term 'benefit' used on consent forms should be defined more accurately at the time of initial consent. It is advisable to differentiate a potential benefit associated with closer medical follow-up, which is inherent to the methodological requirements of the research, from the possible benefit associated with the results, that is the early detection of complications and the intrinsic efficacy of treatment. The latter is uncertain and remains subjective both scientifically and in terms of application delay. We think that it would be better to talk about 'possible benefit' and to avoid the term 'direct individual benefit' as previously recommended by the French law concerning biomedical research until 2004. ${ }^{32}$ Our results are compatible with the new formulation of the law proposed in 2004 in which the term 'expected benefit' is preferred. ${ }^{33}$ This term conveys the idea of incertitude about benefit. This is even more relevant given that this notion can change over time and depending on the research protocol. The questions raised in pharmacogenetics are sensitive because of the highly symbolic representation of genetics dealing with the individual privacy together with a familial dimension. There is also the uncertain nature of the individual benefit to the participant depending on the gene studied.

Furthermore, concerning the potential benefits issued from the research results, our study highlights three cases: (1) The benefit to the participant is obvious and the communication of results would not generate anxiety. The result might then be given to the participant. (2) The result might be useful for the patient's care but is associated with a poor prognosis and is predictive of an increased risk of morbidity or mortality. The principle of duty to inform ${ }^{34,35}$ should then be applied even though this is delicate. (3) The result has no demonstrated impact for care. Feedback should then be considered only if the participant has 
expressed the wish to be informed of the results in the conditions proposed in the research protocol. In all cases, the participant's decision not to be informed should be taken into account remembering that his/her point of view can differ from that expressed initially. In addition, the most appropriate communication strategy needs to be defined. These situations show that, even if it is logical to tend towards giving research participants as much information as possible, it is not clear that this is beneficial for the patients. In APROCO, each patient was asked to state in the informed consent form whether he/she wished to be informed of the results. ${ }^{12}$ This formulation does not distinguish between beneficial results and results associated with a poor prognosis. The APROCO research group currently thinks that the consent form needs to be revised so that it no longer asks participants whether they wish to receive their results, but instead informs them that the results will be transmitted via their clinical physician if they could have a recognised and validated clinical impact. This would allow doctors to explain the results and to modify them according to the patient's clinical situation and psychological state, as is the case with all medical test results. Thus, our work shows that results should be returned to participants as part of the doctor-patient relationship. So, results could be modulated by clinicians as outlined in the French Code of Deontology, which states that a patient's condition can temporarily be kept secret for his own protection. ${ }^{36}$

\section{Importance of continuously providing information}

Our results highlight the importance of providing information regularly and continuously, to keep the participants updated of how research is progressing over time, to inform them about the choice of new markers and to discuss the expected benefits. Furthermore, the importance of delivering information continuously is to take into account the gap between the time in which the participants expect research results and the real time taken to obtain them.

This approach, which meets the demands of patients' associations, has been adopted in the APROCO cohort where information is provided through consultations and through a bulletin written for patients. Establishing a partnership between participants and researchers improves compliance with protocols. Furthermore, this attitude is necessary to ensure that the consent obtained upon inclusion remains informed and valid over time when scientific choices change.

\section{Transfer of research results to clinical situations}

These questions highlight the therapeutic orientation of clinical research ${ }^{37}$ and the conditions for the use of pharmacogenetic research results in a clinical approach. Five essential conditions are recognised for the communication of individual results: ${ }^{29,38}$ the desire of the person giving the sample to know, the scientific validation and confirmation of the results, the results having a significant implication for the health of individuals, the existence of means of prevention or treatment and the possibility of a consultation with a professional expert in the domain. Accordingly, it will be essential to determine who will evaluate the medical impact and how. As is the case in this study, a multidisciplinary steering committee (ethics experts, lawyers and representatives of patients' associations) could meet to identify the most significant results, to plan their validation, to decide whether to diffuse them individually and to organise the transition towards individual feedback. It is essential to separate the returning of global results from individual results. The time taken to validate the procedures for the transition from global to individual results should also be used to educate the participants about the consequences of having access to individual results. They need to be told about the impact on their healthcare and about the risks of undue pressure from employers, insurers, or both that my not be in their interest (benefit-risk ratio). This question relates to a fundamental ethical rule that, as for any other medical data, research data should not be communicated to third parties. ${ }^{39}$

Once the choice to communicate results has been taken, it is necessary to revalidate the data in a nonanonymous fashion by accredited laboratories, which requires considerable financial and logistic organisation. This would involve ensuring the traceability of participants so that they can be contacted and the development of pedagogical tools adapted to clinical situations, as described for cancer patients. ${ }^{40}$ The results of research in pharmacogenetics could be discussed during consultations, making it possible to place these results concerning polymorphisms (different from the situation for single-gene diseases) within the context of other clinical and biological results, thereby illustrating their relative impact on the overall management of the disease. Furthermore, the possibility of giving participants priority access to the therapeutic benefits of research should be considered.

In conclusion, in accordance with current discussions about the communication of results in clinical research, our work applied to pharmacogenetics in the field of HIV infection highlights the need to integrate into research protocols the ethical stakes relating to information procedures.

\footnotetext{
Acknowledgements

We thank Bruno Spire and Françoise Thuret for their help in developing and validating the questionnaire for participants, all those who participated in distributing this questionnaire at the centres and the patients of the APROCO cohort. We also thank all the professionals of the cohort who agreed to be interviewed. The following centres participated in the study (co-ordinators): Besançon (Dr Estavoyer, Pr Laurent, Pr Vuitton), Bordeaux (Pr Dupon, Pr Ragnaud),
} 
Brest (Pr Garré), Caen (Pr Bazin), Corbeil Essonnes (Dr Devidas), Lyon (Pr Peyramond), Nancy (Pr May), Nantes (Pr Raffi), Nice (Pr Cassuto, Pr Dellamonica), Paris (Pr Bricaire, Dr Picard, Pr Herson, Pr Meyohas, Pr Rozenbaum, Pr Salmon Ceron, Pr Vildé), Poitiers (Pr Becq-Giraudon), Saint-Etienne (Pr Lucht).

The APROCO-COPILOTE Study Group is composed of the following: Scientific Committee: Steering Committee: Principal Investigators: C Leport, F Raffi; Methodology: G Chêne, R Salamon; Social Sciences: J-P Moatti, J Pierret, B Spire; Virology: F Brun-Vézinet, $H$ Fleury, B Masquelier; Pharmacology G Peytavin, $R$ Garraffo; Other members: D Costagliola, P Dellamonica, C Katlama, L Meyer, $M$ Morin, D Salmon, A Sobel; DNA bank Monitoring Committee: $C$ Leport, F Raffi, I Theodorou, G Chêne, R Salamon, G Peytavin, F Brun-Vezinet, JP Moatti, F Thuret, C Hervé, G Moutel, $S$ de Montgolfier, N Duchange, F Dreyfus-Netter, C Grillot-Courvalin. Events Validation Committee: L Cuzin, M Dupon, X Duval, V Le Moing, B Marchou, T May, P Morlat, C Rabaud, A WaldnerCombernoux; Project manager: $C$ Lewden; Observers: M Garré, J-F Delfraissy, J Dormont, C Grillot-Courvalin, Y Souterrand, J-L Vildé; Data monitoring and statistical analysis: $C$ Alfaro, $F$ Alkaied, $C$ Barennes, $S$ Boucherit, A-D Bouhnik, C Brunet-François, M-P Carrieri, A-S Chabaud, J-F Cocallemen, J-L Ecobichon, V El Fouikar, V Journot, $R$ Lassalle, J-P Legrand, E Pereira, $V$ Villes, $R$ Winum, $H$ Zouari; Promotion: Agence Nationale de Recherches sur le Sida (ANRS, Coordinating Action no. 7). Other supports: Collège des Universitaires de Maladies Infectieuses et Tropicales (CMIT, ex APPIT), Sidaction, Ensemble contre le Sida, and associated pharmaceutical companies: Abbott, Boehringer-Ingelheim, Roche, Bristol-Myers Squibb, Glaxo-SmithKline, Merck Sharp and Dohme, Roche.

\section{References}

1 Quirk E, McLeod H, Powderly W: The pharmacogenetics of antiretroviral therapy: a review of studies to date. Clin Infect Dis 2004; 39: 98-106.

2 Telenti A, Furrer H: The genetics HIV cohort of the Swiss HIV Cohort Study - facing the new challenges in medicine. Ther Umsch 2004; 61: 613-618.

3 Galvani AP, Novembre J: The evolutionary history of the CCR5Delta32 HIV-resistance mutation. Microbes Infect 2005; 7: 302-309.

4 Martin AM, Nolan D, Gaudieri S et al: Predisposition to abacavir hypersensitivity conferred by HLA-B ${ }^{\star} 701$ and a haplotypic Hsp70-Hom variant. Proc Natl Acad Sci USA 2004; 101: $4180-4185$.

5 Nuffield Council on Bioethics: Pharmacogenetics. Ethical Issues 2003, http://www.nuffieldbioethics.org/.

6 Corrigan OP: Pharmacogenetics, ethical issues: review of the Nuffield Council on Bioethics Report. J Med Ethics 2005; 31: $144-148$.

7 RMGA: Statements of principles on the ethical conduct of human research involving population, 2003, http://www.rmga.qc.ca/.

8 Callies I, Moutel G, Duchange N, Sharara L, Herve C: Communication of the results to those participating in biomedical research. New obligations and interrogations in France. Presse Med 2003; 32: 917-918.

9 Fernandez CV, Kodish E, Weijer C: Informing study participants of research results: an ethical imperative. IRB 2003; 25: 12-19.

10 Mann H: Research ethics committees and public dissemination of clinical trial results. Lancet 2002; 360: 406-408.

11 Partridge AH, Winer EP: Informing clinical trial participants about study results. JAMA 2002; 288: 363-365.

12 de Montgolfier S, Moutel G, Duchange N, Theodorou I, Herve C, Leport C: Ethical reflections on pharmacogenetics and DNA banking in a cohort of HIV-infected patients. Pharmacogenetics 2002; 12: 667-675.
13 Clarke A, English V, Harris H, Wells F: Ethical considerations. Report of the Ethics Sub-group of the Pharmacogenetics Working Party, Society of Pharmaceutical Medicine. Int J Phamaceutical Med 2001; 15: 89-94.

14 Ast O, Luke W: Pharmacogenomics of HIV. Curr Opin Mol Ther 2004; 6: 302-307.

15 Martin AM, Nolan D, Gaudieri S, Phillips E, Mallal S: Pharmacogenetics of antiretroviral therapy: genetic variation of response and toxicity. Pharmacogenomics 2004; 5: 643-655.

16 Pich J, Carne X, Arnaiz JA, Gomez B, Trilla A, Rodes J: Role of a research ethics committee in follow-up and publication of results. Lancet 2003; 361: 1015-1016.

17 Antes G, Chalmers I: Under-reporting of clinical trials is unethical. Lancet 2003; 361: 978-979.

18 Appelbaum PS: Clarifying the ethics of clinical research: a path toward avoiding the therapeutic misconception. Am J Bioeth 2002; 2: 22-23.

19 Le Moing V, Chene G, Masquelier B et al: Definition of virologic response and the type of assay used for quantification of viral load may influence the proportion of responders to antiretroviral therapy. APROCO Study Group. J Acquir Immune Defic Syndr 2000; 24: 82-83.

20 Duran S, Saves M, Spire B et al: Failure to maintain long-term adherence to highly active antiretroviral therapy: the role of lipodystrophy. Aids 2001; 15: 2441-2444.

21 Saves M, Raffi F, Capeau J et al: Factors related to lipodystrophy and metabolic alterations in patients with human immunodeficiency virus infection receiving highly active antiretroviral therapy. Clin Infect Dis 2002; 34: 1396-1405.

22 Spire B, Duran S, Souville M, Leport C, Raffi F, Moatti JP: Adherence to highly active antiretroviral therapies (HAART) in HIV-infected patients: from a predictive to a dynamic approach. Soc Sci Med 2002; 54: 1481-1496.

23 Meyer L, Magierowska M, Hubert JB et al: Early protective effect of CCR-5 delta 32 heterozygosity on HIV-1 disease progression: relationship with viral load. The SEROCO Study Group. Aids 1997; 11: F73-78.

24 Dean M, Carrington M, Winkler C et al: Genetic restriction of HIV-1 infection and progression to AIDS by a deletion allele of the CKR5 structural gene. Hemophilia Growth and Development Study, Multicenter AIDS Cohort Study, Multicenter Hemophilia Cohort Study, San Francisco City Cohort, ALIVE Study. Science 1996; 273: 1856-1862.

25 Wolf CR, Smith G, Smith RL: Science, medicine, and the future: pharmacogenetics. BMJ 2000; 320: 987-990.

26 Brockmoller J, Kirchheiner J, Meisel C, Roots I: Pharmacogenetic diagnostics of cytochrome $\mathrm{P} 450$ polymorphisms in clinical drug development and in drug treatment. Pharmacogenomics 2000; 1: $125-151$.

27 Clarke A, English V, Harris H, wells F: Ethical considerations. Report of the Ethics Sub-group of the Pharmacogenetics Working Party, Society of Pharmaceutical Medicine. Int J Pharmaceutical Med 2001; 15: 89-94.

28 Fernandez CV, Kodish E, Shurin S, Weijer C: Offering to return results to research participants: attitudes and needs of principal investigators in the Children's Oncology Group. J Pediatr Hematol Oncol 2003; 25: 704-708.

29 NBAC: National Bioethics Advisory Commission: Report on research involving human biological materials: ethical issues and policy guidance, 1999, http://www.georgetown.edu/research/nrcbl/nbac/hbm.pdf.

30 France: Law no 2002-303 of March 4, 2002 on the Rights of sick persons. JO Répub Franç no 54, 5 Mars 2002; p 4118 www. legifrance.gouv.fr.

31 World Medical Association: Declaration of Helsinki. Ethical Principles for Medical Research Involving Human Subjects: Tokyo, 2004, http://www.wma.net/e/policy/b3.htm.

32 France: Law No 88-1138 of December 20th, 1988 on the protection of persons accepting biomedical research 
(Huriet-Sérusclat Law) revised July 25th, 1994. Journal Officiel 26 juillet 1994; 10747-10749. www.legifrance.gouv.fr.

33 France: Law no 2004-806 of August 9th 2004 on the new French public health politics. JO Répub Franç, August 11th 2004; 14277 www.legifrance.gouv.fr.

34 Hunter AG, Sharpe N, Mullen M, Meschino WS: Ethical, legal, and practical concerns about recontacting patients to inform them of new information: the case in medical genetics. Am J Med Genet 2001; 103: 265-276.

35 Knoppers BM: Duty to recontact: a legal harbinger? Am J Med Genet 2001; 103: 277.

36 France: Code de déontologie médicale. Decree no 95-1000 of september 6th, 1995 modified by decree no 97-503 of may, 21th 1997; Available from: www.conseil-national.medecin.fr.
37 Miller FG, Rosenstein DL: The therapeutic orientation to clinical trials. N Engl J Med 2003; 348: 1383-1386.

38 Cazé-de Montgolfier S: Collecte, stockage et utilisation des produits du corps humain dans le cadre de recherches en génétique : état des lieux historique, éthique et juridique. Analyse des pratiques au sein des biothèques. Thèse d'éthique médicale et biologique, Paris V, 2002, Available from: www.inserm. fr/ethique.

39 Joly Y, Knoppers BM, Nguyen MT: Stored tissue samples: through the confidentiality maze. Pharmacogenomics J 2005; 5: 2-5.

40 Julian-Reynier C, Welkenhuysen M, Hagoel L, Decruyenaere M, Hopwood P: Risk communication strategies: state of the art and effectiveness in the context of cancer genetic services. Eur J Hum Genet 2003; 11: $725-736$. 